\title{
ANALOGÍAS DE LA HISTORIA I: JULIAN ASSANGE $Y$ WIKILEAKS vS DANIEL ELLSBERG Y LOS PENTAGON PAPERS
}

Carlos Sánchez Hernández

Universidad Complutense de Madrid

En Noviembre de 2010 el mundo entero contempló estupefacto el espectáculo de 250.000 documentos clasificados como "alto secreto", la mayoría pertenecientes al gobierno de Estados Unidos, que mostraban al mundo y de forma desnuda los entresijos de los últimos años de la diplomacia mundial, y en su vertiente más oscura. El responsable de la mayor filtración de documentos oficiales de la historia era Julian Assange, un "hacker" informático experto en indagar en material secreto e inaccesible, que creó en Diciembre de 2006 "Wikileaks" (aunque inició sus actividades en Julio de 2007), una red de información a nivel mundial y a modo de foro que cuenta con hasta tres millones de colaboradores y potencialmente cientos e incluso miles de millones de lectores.

En este trabajo se analizan las enormes similitudes entre esta enorme filtración de secretos oficiales llevada a cabo por Wikileaks a lo largo de 2010, y la sorprendente filtración que hizo Daniel Ellsberg en 1971, ambos hechos enclavados en sendas guerras que a su vez tienen también grandes similitudes: la Guerra de Vietnam y la actual Guerra Contra el Terrorismo escenificada en Irak y Afganistán.

\section{Julian Assange}

El paralelismo entre las figuras de Daniel Ellsberg y Julian Assange, aún estando separadas sus acciones por cuarenta años, es enorme, si bien los contextos históricos que ambos vivieron tienen matices distintos. Igualmente hay un cierto paralelismo entre la implicación estadounidense en la Guerra de Vietnam (1964-73) y en la Guerra de Afganistán e Irak (2001-2011), no tanto en las raíces y las motivaciones de ambas intervenciones militares como en las 
tergiversaciones y mentiras oficiales vertidas desde los "pasillos del poder de Washington".

Julian Paul Assange nació en Townsville, Australia, el 3 de Julio de 1971 (curiosamente dieciocho días después de que Ellsberg llevara a cabo su filtración de los Pentagon Papers). De profesión periodista y con avanzados conocimientos informáticos, ha dado muestras de un gran activismo, y en la actualidad es "la cara pública" de un fenómeno que él mismo ha creado: Wikileaks. Ya desde su adolescencia se sintió atraído por el fenómeno de los "hacker" ó piratas informáticos, llegando a pertenecer en 1991 a un grupo de ésta tendencia, por lo que la policía australiana llegó a asaltar su casa. Fue detenido por penetrar en los archivos de una universidad, de una compañía de telecomunicaciones, por lo que fue sentenciado a una pequeña condena, multado y posteriormente liberado por buena conducta. Es programador y "hacker", y tiene conocimientos de matemáticas, filosofía y física

Trabajó en varias empresas dedicadas al software, hasta que en 2006 se concentró en el proyecto Wikileaks. Desde mediados de 2010 su país, Australia, le ha retirado el pasaporte, y Estados Unidos no ha negado su intención de detenerle. Si bien su activismo es indudable, y se adivina entre sus intenciones unos ribetes idealistas, para la mayoría es aún hoy una incógnita su verdadera motivación: denunciar las mentiras oficiales en las modernas democracias occidentales (como Ellsberg en 1971), afán de notoriedad, o simplemente crear una gran empresa mediática a escala planetaria que finalmente le haga millonario. Se especula con todas éstas versiones ante lo misterioso de éste personaje. Además, a finales de Diciembre de 2010 trascendió que había aceptado una oferta de 1,1 millones de euros por sus memorias, un "borrón" para los que lo consideran un idealista, si bien conviene recordar que Wikileaks no recibe ingresos más que en forma de donaciones, y nunca provenientes de gobiernos o empresas (para preservar así su independencia), tan sólo de particulares, y que Assange está haciendo frente desde Diciembre de 2010 a un costosísimo proceso judicial en el que ya lleva gastados 300.000 euros, y que podría costarle hasta un millón de euros.

Assange es periodista de profesión, pero su perfil personal y profesional muestran un lado claramente activista. Ya en Julio de 2010 llegó a manifestar: "somos de la opinión de que los abusos de la guerra deberían parar". En esas mismas declaraciones, y refiriéndose a las filtraciones de aquel mes, aseguró que se trataba de revelaciones equivalentes en importancia a los papeles de la Stasi difundidos desde 1990 (la policía secreta de Alemania Oriental). Denunció que en las filtraciones de Julio de 2010 había pruebas de crímenes de guerra, y solicitó "cambios tanto en el plano militar como en el político, y cambios en la forma de juzgar la guerra". Además de su militancia y compromiso, Assange ha demostrado entender las relaciones públicas, y por ello se ha convertido en la cara de Wikileaks, desafiando a gobiernos de todo el mundo, comenzando por el más poderoso, el estadounidense.

Algunos de los puntos más oscuros, tanto de Assange como de Wikileaks, son el hecho de que en varios ejercicios fiscales, y habiendo recibido hasta un millón de dólares en donativos particulares, Wikileaks nunca ha presentado sus 
cuentas en público, un hecho cuanto menos, sospechoso. Otra crítica, proveniente además de una antigua colaboradora de Wikileaks, es la que se refiere al supuesto estilo autoritario de Assange en la forma de dirigir la organización. Un último punto oscuro en la biografía de Assange, al margen de sus problemas con la justicia australiana en su juventud, es la denuncia que tiene pendiente en Suecia por supuestos delitos sexuales, por lo que fue detenido en Gran Bretaña en Diciembre de 2010, y tras negársele la fianza fue puesto en libertad condicional y vigilada en ese país. Sus incondicionales denuncian que tras las denuncias de la fiscalía sueca, está la mano de Estados Unidos, que pretende detenerlo, y de momento inmovilizarlo en sus actividades.

\section{$\underline{\text { Wikileaks }}$}

Se trata de una página web que dice servir a la verdad y usar la transparencia, si bien algunos críticos la acusan precisamente de lo contrario, de actuar amparándose en la opacidad. Sus responsables no han sido explícitos en su exacto funcionamiento (tal vez para protegerse y protegerla), incluso a la hora de aclarar quiénes la integran, de qué fondos dispone ni qué medios ni criterios emplea para publicar sus revelaciones. Wikileaks se nutre principalmente de envíos anónimos, y cualquier usuario de Internet del mundo puede enviar información clasificada y secreta que haya obtenido (si bien no se suele preguntar de qué modo) para "compartirla" con otros usuarios, y los administradores de Wikileaks deciden sobre la veracidad y fiabilidad de los documentos enviados para publicarlos o no. De ésta forma, y desde 2007, se han filtrado documentos que han puesto en evidencia a gobiernos, se han revelado masacres, y se ha mostrado el cinismo de determinados políticos; y es raro el gobierno occidental que no se ha visto salpicado por alguna revelación que le afectase directa o indirectamente.

Wikileaks, término acuñado del idioma inglés como "espacio Wiki" (ya habitual en la red) y "leak" ("fuga ó filtración") es una organización nacida entre 2006 y 2007, fundada por un nutrido grupo de personas comprometidas con la verdad, y entre las que destacan periodistas, expertos en alta tecnología, matemáticos, disidentes chinos (el mayor régimen totalitario del mundo en la actualidad) y profesionales mediáticos de diverso tipo de EE.UU, Australia, China, Europa, e incluso Sudáfrica. Pero está dirigida por un personaje que se ha convertido en su "alma Mater", el periodista australiano Julian Assange, editor-jefe y director. Assange saltó a la fama mundial, tras anunciarse las importantes y más amplias filtraciones de la historia, sobre la Guerra Contra el Terrorismo en Noviembre de 2010, y tras ser detenido el 7 de Diciembre de 2010. Desde su detención el portavoz de Wikileaks es Kristinn Hrafnsson, quien lidera el proyecto.

Wikileaks se dedica a la captación y publicación de todo tipo de informes y de documentos oficiales basados en todo tipo de ámbitos: la política exterior y política militar de los Estados, la mayoría de alto secreto, la economía, los centros de poder económicos ó políticos, todo a escala mundial. La editorial, o al menos la marca, que está tras éste proyecto es "The Sunshine Press". Por 
medio de su sitio web, publica de forma anónima informes y documentos filtrados, muchos de ellos conseguidos por "hackers" (piratas informáticos que rastrean bases de datos y penetran en ellas captando información), lo cual le ha valido la descalificación desde algunos ámbitos al considerar que basa parte de sus fuentes en el delito. Desde el inicio de sus actividades, Wikileaks ha acumulado hasta 1,2 millones de documentos. Wikileaks no tiene una oficina física, y tampoco tiene empleados con salario como una empresa de comunicación tradicional.

Wikileaks acoge entre sus colaboradores a cualquiera que se ofrezca a aportar filtraciones que revelen comportamientos no éticos por parte de gobiernos, poniendo especial énfasis en países con regímenes totalitarios, pero también por parte de empresas multinacionales que violen la ética en sus prácticas. Pero ha sido a finales de 2010 cuando Wikileaks ha alcanzado notoriedad mundial tras filtrar y difundir hasta un cuarto de millón de documentos oficiales y secretos sobre la política exterior y la política militar de Estados Unidos, y en concreto las actividades centradas en las guerras de Irak y Afganistán. A pesar de su nombre, no se trata de un "espacio Wiki" habitual, ya que los lectores que no tienen las licencias correspondientes no pueden alterar sus contenidos. Wikileaks usa una versión del software "MediaWiki", aparte de usar determinados programas para proteger el anonimato de sus informantes. Documentos especialmente sensibles han sido una serie de cables, en concreto 26.000, del Departamento de Estado y clasificados como "top secret", concernientes a información crítica para los planificadores estadounidenses de la guerra, con estimaciones sobre la marcha en los dos frentes de guerra, unos documentos filtrados a Wikileaks por el soldado norteamericano Bradley Manning, detenido por el Ejército de EE.UU.

Todo el entramado de Wikileaks cuesta, lógicamente, dinero; el propio Assange calculó en unos 200.000 euros anuales el coste tan sólo de hacer funcionar Wikileaks, y en 600.000 euros el coste de mantener la empresa. Para financiarse, Wikileaks ha firmado acuerdos de exclusividad en varios países, y Assange no descarta establecer una fórmula de subasta de la información, para vendérsela al mejor postor y que sean los medios los que decidan su valor, y obtener así dinero con el que sostener a una empresa que por lo demás funciona financieramente casi como una ONG.

Wikileaks ha recibido algunos galardones por su labor: en 2008 la prestigiosa revista británica "The Economist" le concedió un premio dedicado a los nuevos medios, y en 2009 fue premiada por Amnistía Internacional por unos documentos que revelaban ejecuciones sumarias en Kenya.

\section{Las Filtraciones Más Importantes de Wikileaks: 2010}

A lo largo de 2010, Wikileaks ha saltado al primer plano mundial por la importancia de sus actividades, alertando a innumerables gobiernos (y no sólo de regímenes totalitarios, también a democracias), fundamentalmente al de Estados Unidos, por sus filtraciones sobre la Guerra de Irak y la Guerra de Afganistán. En lo referente a Afganistán, una guerra en 2002 parecía estar bajo 
control y en 2011 parece estar en peores condiciones que nunca, las filtraciones revelan las dificultades y las amenazas a las que se enfrenta la OTAN y Estados Unidos casi a diario, dando un punto de vista muy distinto y desde luego mucho más pesimista del que dan las autoridades militares estadounidenses. La batalla por "ganar los corazones y las mentes de los afganos" es una batalla casi perdida, y los objetivos militares parecen no alcanzarse nunca.

En Abril de 2010 se produjo la primera gran filtración; se trataba de un dramático vídeo gravado desde un helicóptero Apache estadounidense (vídeo por supuesto censurado militarmente por el Ejército Estadounidense) en el que se observa el asesinato, supuestamente por error, de dos periodistas en Bagdad que cubrían la guerra. El vídeo data del 12 de Julio de 2007, fecha del suceso, y no sólo mueren los dos periodistas, que trabajaban para la agencia de noticias Reuters, sino que mueren otras nueve personas que estaban a su lado y trataban de retirar muertos y heridos del suelo. En el vídeo se observa claramente como las once personas no hacen ningún movimiento que indique que se disponían a atacar al helicóptero desde el que se les dispara, ya que ni siquiera lo miran. Reuters solicitó varias veces el vídeo sin éxito, ya que el Ejército de Estados Unidos o bien negaba su existencia ó bien se negaba a entregarlo aduciendo que se trataba de material secreto. Finalmente Wikileaks lo consiguió y lo filtró.

En Julio de 2010 tuvo lugar la segunda gran filtración sobre la Guerra Contra el Terrorismo, ésta vez en el escenario de Afganistán; los prestigiosos periódicos "The Guardian" (británico), "The New York Times" (norteamericano) y "Der Spiegel" (alemán) publicaron conjuntamente 92.000 documentos sobre la Guerra de Afganistán referidos a los años 2004 a 2009 (justo antes de que el presidente Obama anunciase su nueva estrategia para el conflicto), documentos todos ellos logrados gracias a Wikileaks. Ésta filtración se daría a conocer como "los Papeles de Afganistán", e ilustraba claramente el fracaso de una guerra demasiado prolongada (entonces ya duraba casi nueve años), y en la que se aportaban alarmantes pruebas sobre el doble juego de Pakistán, un actor determinante históricamente en todo lo relativo a Afganistán desde hace treinta años (desde la invasión soviética), que si bien es aliado de EE.UU y la OTAN, tiene sin embargo a espías del gobierno planificando con los talibanes e incluso con Al-Qaeda ataques suicidas contra las tropas de la OTAN.

En ésta filtración de Julio de 2010 se detallaban aspectos poco conocidos de la guerra, pero sobretodo el lado más oscuro de todos ellos, y que dañaba la imagen de las tropas estadounidenses y de otros países aliados en Afganistán: muertos civiles e inocentes provocados por soldados mayoritariamente norteamericanos, víctimas del "fuego amigo", e indicios de que desde 2009, los planificadores estadounidenses, viéndose impotentes para controlar Afganistán, comenzaron a escoger a grupos de Talibanes moderados para adiestrarlos como futuros dirigentes del país, bajo el curioso y eufemístico calificativo de "Talibanes buenos". También la filtración detallaba las operaciones encubiertas para planificar el asesinato selectivo de líderes insurgentes afganos vivos o muertos por la "Task Force 373", una unidad secreta de la OTAN. Igualmente se daba cuenta del descubrimiento del 
sofisticado arsenal con el que cuentan los talibanes (parte de él dejado por los estadounidenses en Afganistán tras la retirada soviética en 1989) que podría incluír a los sofisticados misiles tierra-aire Stinger que derribaron en los 1980's miles de helicópteros soviéticos, y el fracaso de una de las grandes innovaciones de la Guerra de Afganistán, los aviones no tripulados y armados, presentados por el Pentágono como un gran avance en la guerra y de los que el Ejército Estadounidense está utilizando en Afganistán en torno a 20 de los modelos Predator y Reaper. Estados Unidos acusó entonces a Wikileaks, por boca del Consejero de Seguridad Nacional, el general James Jones, de poner en peligro la vida de civiles que colaboraron en la elaboración de informes militares, si bien Wikileaks respondió que trató de informar a los norteamericanos de la publicación de éstos documentos una semana antes de que se produjeran, sin obtener respuesta alguna. Los periódicos a los que Wikileaks filtró éstos documentos respondieron que los analizaron antes de publicarlos, y que no hallaron nada que pudiera comprometer a las fuerzas aliadas en Afganistán. La propia Casa Blanca condenó la publicación de éstos documentos argumentando que comprometían la seguridad nacional, y anunciando que pondría en marcha una investigación sobre el origen de la filtración, lamentando además que los periódicos a los que Wikileaks proporcionó la filtración no se pusieran en contacto con el gobierno estadounidense antes de su publicación para consultar sobre su naturaleza y posible peligrosidad.

La filtración de Julio de 2010 presentaba claramente cómo los objetivos de la Guerra de Afganistán en ningún caso se han logrado: desde que el 7 de Octubre de 2001 el entonces Presidente Bush lanzara la Operación Libertad Duradera, una macro-operación militar en Afganistán contra los talibanes para terminar con ellos y con Al-Qaeda, todavía con el "shock" del 11-S muy reciente, tras nueve años de guerra en ese país, 300.000 millones de dólares gastados por el contribuyente de Estados Unidos, casi 80.000 militares estadounidenses presentes en 2010 en Afganistán, y otros 40.000 de veinte países más, y el apoyo (al menos formal) de Rusia y los países vecinos de Afganistán y aliados de EE.UU, tras todo eso, los talibanes eran en 2010, sin que pareciera una hipérbole, más fuertes que nunca (tal como afirmó el New York Times), revelando el total fracaso en la estrategia de Estados Unidos para éste país.

Otra filtración importante fue la llevada a cabo en Octubre de 2010 sobre la Guerra de Irak. Bajo el título de "Irak War Logs" (documentos de la Guerra de Irak), se trató de la mayor filtración de documentos clasificados de una sola vez de la historia, con un total de 392.000 documentos filtrados desde el Pentágono referidos a Irak entre los años 2004 a 2009. En ellos se revela el uso sistemático de la tortura, la filtración de un número de bajas cifrado oficialmente hasta el 31 de Diciembre de 2009 en 109.032, de los que 66.081 (el 63\%) son civiles iraquíes, 23.984 combatientes enemigos calificados como "insurgentes", 15.196 fuerzas militares y policiales del gobierno aliado de Irak, y 3.771 fuerzas estadounidenses (una cifra que a mediados de 2011 ronda ya los 5.000 soldados estadounidenses muertos). Éstos documentos también se refieren a la batalla de Faluya, un choque entre insurgentes iraquíes y tropas estadounidenses producido en Abril de 2004 en esa ciudad tras el asesinato de 
cuatro norteamericanos allí, choque en el que murieron 40 soldados estadounidenses y más de mil insurgentes, y que el Pentágono calificaba como "el episodio militar de implicación estadounidense más importante y extenso desde la Operación Juntion City (1967) y la Ofensiva Tet (1968)", ambas de la Guerra de Vietnam. Igualmente, también los documentos aludían a la ayuda que Irán presta a los insurgentes chiíes de Irak. Varios periódicos se hicieron eco de éstas filtraciones de Wikileaks, en concreto, además de los tres anteriormente mencionados, también publicaron éstas investigaciones el francés "Le Monde" y el español "El País".

Assange destacó que éstos documentos filtrados reflejan fielmente la realidad sobre la Guerra de Irak. Los estadounidenses dejaron sin investigar multitud de informes que denunciaban abusos, torturas, violaciones e incluso asesinatos tanto de las fuerzas estadounidenses como de sus aliados del ejército iraquí, y aún a pesar de la insistencia de los dirigentes militares norteamericanos y británicos de la no existencia de un registro oficial de víctimas. Y lo peor es que los informes clasificados filtrados ponen en evidencia el conocimiento que el Pentágono y las autoridades militares estadounidenses tenían de todos los abusos cometidos, si bien no hay certeza de la participación directa de militares estadounidenses en ello aunque sí de que usaran a las fuerzas iraquíes para conseguir información mediante esos abusos.

La segunda mayor filtración de todas, y posiblemente la mayor de la historia en cuanto a la importancia y trascendencia de su contenido, tuvo lugar el 28 de Noviembre de 2010, cuando Wikileaks filtró a la prensa de un solo golpe un total de 251.187 cables o comunicaciones entre el Departamento de Estado y sus embajadas por todo el mundo, los denominados oficialmente "United States Diplomatic Cables Leak", y más coloquialmente "Cablegates". Ésta cantidad de documentos la filtró Wikileaks a los diarios "The New York Times", "The Guardian", "Le Monde", "El País", y "Der Spiegel". Éste cuarto de millón de documentos no sólo se refería a los escenarios de Irak y Afganistán, sino también a infinidad de gobiernos de Europa, Rusia, Latinoamérica y Asia, incluyendo perfiles de sus mandatarios y primeros ministros, y también análisis y reflexiones sobre las repercusiones de los perfiles personales de los líderes mundiales sobre la política estadounidense. Por todo ello, por su tamaño y trascendencia, la publicación de éstos documentos causó una gran sensación y alarma en el gobierno de EE.UU, tal como declaró la propia Secretaria de Estado, Hillary Clinton.

El mayor valor y la mayor contribución de las filtraciones de Wikileaks sobre Irak y Afganistán es el poner en conocimiento del gran público de todo el mundo lo que sólo sabía el gobierno de EE.UU, el poder evaluar públicamente la marcha de una controvertida guerra, la conveniencia o no de sus críticas, así como las dudas sobre la prolongación y utilidad de ésta; y todo a tenor de las constantes invocaciones al 11-S que desde 2001 han hecho la Administración Bush (y también, aunque menos, la propia Administración Obama), una prueba incuestionable de que Estados Unidos precisa de recordar motivaciones a su opinión pública ante la evidente muestra de pérdida de sentido del conflicto. En éste año de 2011, en el mes de Octubre, la intervención de EE.UU en Afganistán cumplirá 10 años, toda una década; en Vietnam, Nixon firmó un 
tratado de paz y retiró todas las tropas estadounidenses del país en 1973 cuando aún no se había cumplido una década de la intervención masiva de EE.UU en Vietnam (1964). Mientras, la presencia militar estadounidense en Afganistán continúa tras todo éste tiempo, y la guerra tendrá inevitablemente que ser re-evaluada. Si los documentos filtrados por Wikileaks facilitan o no el final de la guerra, algo difícil de afirmar, es algo que sólo la historia juzgará.

\section{El Boicot a Wikileaks}

Tras la enorme filtración del 28 de Noviembre de 2010, y los ataques cibernéticos de denegación de servicio que empezó a sufrir, el 30 de Noviembre Wikileaks comenzó a mudar su información a los servidores Amazon EC2 de computación en nube de Amazon. Pero no sólo EE.UU boicoteó Wikileaks, sino que también lo hizo el gobierno de China, que aplicó su tradicional censura extendiéndola a la informática al sentirse perjudicada en los documentos filtrados ante la posibilidad de revelaciones comprometedoras de cables norteamericanos enviados desde las embajadas de EE.UU en Seúl y Pekín refiriéndose al aliado Corea del Norte; los chinos bloquearon los enlaces cibernéticos al sitio web de Wikileaks el 1 de Diciembre.

El 1 de Diciembre, presionado por el gobierno estadounidense, Amazon deja de dar cobertura a Wikileaks. Mediante Twitter, Wikileaks critica a Amazon acusándole de estar en contra de la Primera Enmienda. No sólo es el gobierno, sino que también el propio Congreso Estadounidense quiere hacer desaparecer Wikileaks, prohibiendo su acceso y eliminándolo de Internet para siempre, algo que ya antes había intentado. Se trata de lo que muchos consideran como el mayor ataque a la Primera Enmienda de la historia, en contraste con la actitud casi cuarenta años atrás de la prensa estadounidense con el Asunto Ellsberg, en el que la prensa de Estados Unidos, comenzando por el New York Times, defendió la libertad de prensa publicando infinidad de periódicos, siguiendo al Times, los "Papeles del Pentágono", ante el acoso de la Administración Nixon a la libertad de información.

El acoso institucional contra Wikileaks se refuerza el 2 de Diciembre de 2010 cuando la empresa proveedora EveryDNS rescinde su contrato con Wikileaks cortando su acceso. Francia se suma al acoso, al solicitar su gobierno a OVH que deje de albergar el portal de Wikileaks. El 3 de Diciembre se reforma en EE.UU la ley promulgando la que se conocerá como "Acta SHIELD" (Securing Human Intelligent and Enforcing Lawful Dissemination), que es un endurecimiento del "Acta de Espionaje" que prohíbe la publicación de información clasificada sobre secretos cifrados o comunicaciones internacionales de inteligencia. El 4 de Diciembre, PayPal cancela la cuenta que tenía con Wikileaks y a través de la cual recibía donaciones, bajo el argumento de que no quiere "servir de cobertura para animar a otros a participar en actividades ilegales". El 6 de Diciembre, MasterCard se sumó al boicot anunciando que no aceptará su sistema de pago para Wikileaks, algo parecido a lo que hizo PostFinance, quien también bloqueó la posibilidad de donaciones o pagos a Wikileaks. El 7 de Diciembre también Visa retira su servicio de pagos para Wikileaks. El 9 de Diciembre Twitter canceló la cuenta 
de uno de los grupos de apoyo a Wikileaks, "Anonymous", y después Facebook eliminó la página de Operation Payback de ataques DDoS en defensa de Wikileaks.

El boicot a Wikileaks desde la gran filtración del 28 de Noviembre de 2010 ha sido pues enorme, sumándose empresas privadas a instancias de gobiernos, además del acoso institucional. No hay duda que la divulgación de secretos oficiales, y sobretodo si se hace de forma masiva, constituye un delito, pero tampoco conviene olvidar que las nuevas tecnologías facilitan éstas actividades, y que la transformación de las sociedades modernas pasa por admitir que éstas puedan "digerir" con normalidad el conocimiento de éstos secretos oficiales y en tiempo real, no décadas después de haberse producido los hechos, como sucede habitualmente cuando se desclasifican documentos secretos para la investigación muchos años después de haberse redactado.

Ha trascendido que el Pentágono tiene un equipo compuesto de hasta 120 personas dedicadas en exclusiva a limitar el efecto mediático de las filtraciones de Wikileaks. Éste dato da una idea de la alarma que ha creado entre los planificadores estadounidenses las actividades de Wikileaks. Los responsables del Pentágono argumentan constantemente que las filtraciones ponen en peligro la vida de muchas personas. Otra reacción que da muestra de la alarma creada en EE.UU fue la de la exgobernadora de Alaska y excandidata republicana a la vicepresidencia en 2008, Sarah Palin, quien llegó a solicitar el 29 de Noviembre de 2009 a través de su página en Facebook a la Administración Obama que ordenase la captura de Assange con la misma urgencia con la que se persiguió durante casi diez años al mismísimo Bin Laden (muerto en Mayo de 2011 por los Navy Seals), al representar un enorme peligro para la seguridad nacional estadounidense. Al día siguiente, el presentador de la cadena Fox, Bill O’Reilly, pidió públicamente la pena de muerte para los miembros de Wikileaks y de quienes les filtran los documentos. Incluso un asesor del Primer Ministro de Canadá (país con tropas tanto en Irak como en Afganistán) llegó a decir en la BBC que Assange debería ser asesinado por las actividades de Wikileaks.

\section{Apoyos a Wikileaks y a Assange}

Las muestras de apoyo a Wikileaks sin embargo también han existido, tanto desde Anonymous como desde la empresa de pagos DataCell, que facilitó los pagos para Wikileaks, sin olvidar al portal "geek alt1040" que inició un boicot de Amazon y PayPal por su acoso a Wikileaks. Ya antes de la filtración del 28 de Noviembre de 2010, el presidente de Veterans for Peace, Mike Ferner, publicó una editorial (Julio de 2010) apoyando a Wikileaks. También el columnista John Pilger escribió un editorial en Agosto de 2010 en defensa de Wikileaks, al considerar a éste como "un representante de los intereses de la responsabilidad pública y una nueva forma de periodismo reñida con la dominación y el cinismo ... Assange ha estado realizando una labor propia de un periodista y merece el apoyo de las personas que creen que la democracia se sustenta en el libre flujo de la información". Pilger junto al cineasta británico Ken Loach y otros, se ofrecieron a pagar una fianza millonario que el juez 
impuso a Assange para que saliera en libertad condicional. El también cineasta y documentalista norteamericano, Michael Moore, aportó 20.000 dólares a la fianza de Assange, y se puso a disposición de Wikileaks. También el Premio Nobel de biología en 2002, John Sulston, avaló la fianza.

Han sido varias las plataformas digitales creadas en todo el mundo en favor de la libertad de Assange y contra su detención. Acusan además a los que le persiguen, y sobre todo a EE.UU, de intensificar su acoso y su búsqueda y captura a comienzos de Diciembre de 2010, justo tras la gran filtración del 28 de Noviembre con sus cables diplomáticos confidenciales estadounidenses.

Otro importante y significativo apoyo a Wikileaks llegó de parte de Daniel Ellsberg, el exanalista militar del Pentágono que divulgó en 1971 los "Pentagon Papers". Ellsberg, que desde la década de los 1970's es un ferviente defensor y activista de la libertad de prensa, se ha prodigado en apoyos a Wikileaks. Hasta la fecha, el único político estadounidense en manifestarse públicamente a favor de Wikileaks ha sido el congresista tejano Ron Paul, defendiendo públicamente a Julian Assange con el argumento de que "en una sociedad libre se supone que sepamos la verdad ... en una sociedad donde la verdad se convierte en traición a la patria, entonces estamos en graves problemas". El también congresista por Florida, Connie Mack, también elogió a Wikileaks, aunque sin manifestarse contundentemente en apoyo de las filtraciones. Un político de primera fila mundial que habló a favor de Wikileaks fue el entonces aún presidente de Brasil, Lula da Silva (dejó su cargo en Enero de 2011), quien en Diciembre de 2010 defendió a Wikileaks citándolo como un símbolo de la libertad de expresión, y afirmando que la detención de Julian Assange atenta contra la libertad de expresión. El Ministro australiano de Exteriores, Kevin Rudd, exculpó a Assange de las filtraciones en Diciembre de 2010, declarando que los responsables de éstas fueron quienes las filtraron a Wikileaks, y ésta se limitó a publicarlas.

\section{Daniel Ellsberq: "el hombre más peligroso de América"}

Parafraseando a Henry Kissinger, quien pronunció ésta frase en 1971 refiriéndose a Daniel Ellsberg con ocasión del escándalo de la publicación de los "Pentagon Papers", me referiré brevemente al semblante de un hombre que pasó de héroe a villano para el Departamento de Defensa de EE.UU (y a la inversa para los movimientos antibélicos de la época) en apenas dos años. El título de éste epígrafe corresponde no sólo al calificativo de Kissinger, sino también al espléndido documental que dirigieron Judith Ehrlich y Rick Goldsmith en 2009 narrando ésta apasionante historia que cambiaría para siempre las relaciones entre los gobiernos estadounidenses y la opinión pública y los medios de comunicación de Estados Unidos, en una época, la década de los 1970's, que tras la sobrecargada década anterior de geopolítica y Guerra Fría, y sobre todo de Guerra de Vietnam, se destapó como la década que vería nacer una especie de mayoría de edad de la opinión pública estadounidense, conducida por una prensa cada vez más libre, autónoma respecto a los poderes políticos y mordaz que se alzaría con el liderazgo moral para denunciar hechos promovidos desde el poder, destapándolos, analizándolos y 
desmenuzándolos, obligando finalmente con esos análisis a las instituciones políticas y judiciales a actuar.

Se trata del nacimiento de lo que posteriormente se denominaría "el cuarto poder" (tras los tradicionales tres poderes de Estado, Ejército e Iglesia): los medios de comunicación y la prensa libres que con sus investigaciones y revelaciones con un afán informativo obligaban a los poderes judiciales a actuar. El acontecimiento que inauguraría éste concepto, acontecimiento dado a conocer por el periodismo independiente norteamericano de los 1970's, fue el Escándalo Watergate (1972-74), que acabó provocando la caída y fin de la presidencia de Richard Nixon. Pero el hecho que desencadenó el Watergate fue la publicación en 1971 de los Pentagon Papers por Daniel Ellsberg, de ahí la importancia del personaje.

Daniel Ellsberg nació el 7 de Abril de 1931 en Detroit, en una clásica familia de clase media. Se graduó brillantemente en la Universidad de Harvard, destacando en política y en economía. Ellsberg fue un investigador, analista y académico en Ciencias Políticas, un brillante teórico de las Ciencias Políticas que apuntaba hacia cotas muy altas dada su inteligencia y capacidad de trabajo, si bien en la actualidad se le recuerda fundamentalmente por ser un gran luchador por la libertad de prensa. Sus revelaciones provocarían un enorme terremoto político en Washington, iniciarían el proceso de caída de la Administración Nixon, e iniciarían igualmente la aceleración de la ya acelerada retirada estadounidense de Vietnam, erosionando aún más la ya pésima imagen que la guerra tenía entre los norteamericanos para 1971.

Ellsberg tuvo una brillante etapa académica en Harvard, donde llegó a colaborar académicamente con un entonces desconocido Henry Kissinger, llegando incluso a desarrollar una inteligente teoría en 1959 denominada "paradoja de la decisión", hoy día conocida como "paradoja de Ellsberg". En el ejército sirvió como comandante en los US Marines durante dos años, y tras su formación centrada en política exterior y política militar ingresó en 1964 en una institución de investigación patrocinada por las Fuerzas Armadas, la Rand Corporation, donde destacó como teórico y analista, y en donde se fijó en él un alto funcionario del Departamento de Defensa, John McNauthon, ayudante directo del Secretario de Defensa, Robert S. McNamara. McNauthon le ofreció incluirlo en su equipo en el Pentágono.

Tras su etapa en la Rand Corporation comenzó a trabajar en Agosto de 1964 en el Pentágono justo en el epicentro de la planificación de lo que justo ese año se revelaría como la implicación estadounidense directa en Vietnam. Precisamente el primer día de trabajo de Ellsberg en el Pentágono fue el 4 de Agosto, el día del segundo Incidente del Golfo de Tonkín; Ellsberg recordaría años más tarde como el capitán del navío estadounidense supuestamente atacado por patrulleras norvietnamitas envió un comunicado al Pentágono restándole importancia al supuesto suceso y recomendando que se olvidara ante la imposibilidad de confirmar que el hecho hubiera tenido lugar, justo lo contrario de lo que hizo la Administración Johnson, que lo usó como excusa para lanzar el primer bombardeo contra Vietnam del Norte presentándolo como una represalia, e iniciando así la intervención militar directa de los Estados 
Unidos en Indochina, intervención que llevaba gestándose de forma concreta desde 1959 y que ya fue acelerada por Kennedy desde 1962. Así, desde su primer día en el Pentágono, se fue forjando la idea de Ellsberg de que las mentiras oficiales dominaban muchas de las decisiones gubernamentales.

Ellsberg se convirtió desde el principio en uno de los "arquitectos de la guerra"; el equipo de analistas que trabajaban estrechamente en el Pentágono elaborando informes, planes bélicos y manejando estadísticas literalmente construían la guerra, argumentando de todas las formas posibles en pro de la guerra, redactando tesis e hipótesis que constantemente convencieran al Presidente Johnson y a su equipo de la necesidad de ir a la guerra en Vietnam, dando bases teóricas que enfocaran los procesos de toma de decisiones hacia la intervención militar directa en Vietnam. Tanto el Departamento de Estado, dirigido entonces por Dean Rusk, como fundamentalmente el Departamento de Defensa, encabezado por el todopoderoso y principal arquitecto de la guerra, Robert S. McNamara, usaban todas aquellas argumentaciones suministradas por varios analistas como Ellsberg para convencer a Johnson de que era imperativa una guerra en el Sudeste Asiático contra el comunismo. Ellsberg recuerda como a finales de 1964 en una ocasión le solicitaron con urgencia un informe con detalles "sangrientos" con un incidente en que al menos un norteamericano hubiera muerto en Vietnam (aún sin iniciarse la implicación directa estadounidense en la guerra) para presentárselo al día siguiente al presidente, al objeto de convencerle de la necesidad de inicar el envío de tropas estadounidenses a Vietnam. El propio McNamara felicitaría posteriormente a Ellsberg por lograr ese informe.

Tras elaborar infinidad de informes y análisis sobre la situación en Vietnam, y ya iniciada la implicación, incluso de tropas de tierra estadounidenses, Ellsberg recibió el encargo de McNauthon de viajar a Vietnam para evaluar la situación sobre el terreno. Allí fue donde la perspectiva de Ellsberg sobre la guerra comenzó a cambiar, invirtiéndose completamente al reparar en los errores de cálculo y planificación así como errores históricos (confirmados en los Pentagon Papers) de la intervención de EE.UU. en el Sudeste Asiático desde sus inicios. Ellsberg se convirtió durante casi dos años en prácticamente un soldado más en Vietnam, tomando parte incluso en acciones bélicas a las órdenes del General Edward Lansdale. Al ver la realidad de la guerra sobre el terreno, a diferencia de los demás arquitectos de la guerra de Washington, terminó convenciéndose de que la Guerra de Vietnam, tras varios años de lucha directa de EE.UU, era completamente inviable. En ésta etapa en Vietnam, y tras una perspectiva de implicación personal en la guerra que ya duraba cuatro años, Ellsberg llegó a la conclusión de que incluso los dirigentes de la guerra, comenzando por el propio McNamara (que así lo confirmaría años después) sabían a la altura de 1967-68 que EE.UU no tenía posibilidades racionales de ganar la guerra, derrotar al comunismo en Vietnam y comenzar la retirada, tal como los planes de 1965 habían previsto en su diseño. La base teórica de éstos planes se sustentaba en la idea de golpear tan duramente a los comunistas vietnamitas y a Vietnam del Norte con el enorme poder militar estadounidense, que aquellos no sólo vieran minada su voluntad de lucha, sino que no pudieran reemplazar sus fuerzas perdidas. La realidad era muy distinta, y los dirigentes de la guerra la conocían, pero para 1967 la negaban y no la 
proclamaban en público por consideraciones políticas fundamentalmente internas. En conversaciones dentro del gabinete de Johnson, entre el Secretario de Estado y el propio McNamara, se llegó a admitir la hipocresía de la intervención en Vietnam con ésta afirmación conocida décadas después de pronunciarse: "seguimos en Vietnam en un diez por ciento para ayudar a los vietnamitas, en un veinte por ciento para contener a los chinos, y en un setenta por ciento para salvar la cara en casa".

El propio McNamara, a sabiendas de ésta cruda realidad, continuó afirmando hasta finales de 1967 en público, y a pesar de las miles de bajas, de la prolongación de la guerra, y de su propio convencimiento en la nula posibilidad de victoria, que la victoria estaba cercana. El general Westmoreland, comandante en jefe de todas las fuerzas estadounidenses en Vietnam, siempre afirmaba lo mismo. Ellsberg fue poco a poco dándose cuenta de la prolongación inútil de la guerra simplemente por motivos políticos, y para evitar asumir la derrota.

En éste contexto, los Pentagon Papers que Ellsberg contribuyó a elaborar en su etapa de planificador del Departamento de Defensa (junto a muchos otros planificadores, como un jovencísimo y recientemente fallecido Richard Hoolbroke, el artífice décadas después de la paz de Dayton para Bosnia) y que terminaría filtrando a la prensa en 1971, eran un completo estudio que ordenó a mediados de 1967 un ya titubeante Robert S. McNamara, aún Secretario de Defensa y arquitecto principal de la Guerra de Vietnam, que tras diseñar la guerra mostraba ya por entonces enormes dudas sobre su viabilidad, hasta que dimitió de su cargo en Febrero de 1968, justo tras la Ofensiva Tet. La Ofensiva Tet fue una victoria militar estadounidense, pero un gigantesco fracaso de imagen de cara a la opinión pública de EE.UU, que a pesar de ver cómo sus soldados repelieron la agresión norvietnamita, también vio imágenes como la incursión en la embajada estadounidense en el mismo Saigón, y comprobó la inviabilidad de ésta guerra ya que tras cuatro años de combates y de recibir mensajes optimistas y promesas de victoria, los comunistas vietnamitas aún tenían fuerzas para lanzar ofensivas por todo Vietnam y hasta la capital Saigón. Tras el Tet, la mayoría de los norteamericanos ya no creían en una victoria militar en Vietnam, como su gobierno seguía sosteniendo que ocurría.

Para Ellsberg el Tet y su repercusión no fue ninguna sorpresa. Tras regresar de Vietnam, Ellsberg dejó desilusionado el Pentágono y regresó a la Rand Corporation como experto en Vietnam, tanto en la teoría como sobre el propio terreno, contribuyendo a la elaboración de partes de los Pentagon Papers. Con los Pentagon Papers, también denominados "el Informe McNamara", Robert S. McNamara pretendía la elaboración de un estudio que a modo de resumen e investigación histórica sobre la implicación de EE.UU en Vietnam evaluara y determinara las causas del fracaso, ya evidente a finales de 1967 (incluso antes del Tet), de la intervención militar estadounidense en Vietnam. El nombre técnico original del estudio fue "United States - Vietnam Relations, 1945-1967: a Study Prepared by the Department of Defense". El encargo recayó en la Rand Corporation, una institución de investigación socio-política-militar ubicada en California, patrocinada por el "Complejo Militar-Industrial" estadounidense y dependiente del Departamento de Defensa. Se trataba de un completo estudio 
con los aspectos más secretos y confidenciales de las relaciones entre Estados Unidos y Vietnam, incluyendo cables, telegramas y documentos clasificados como de alto secreto, desde que Washington puso sus ojos en el Sudeste Asiático, en 1945. Resumidamente, éste estudio ponía de relieve los procesos de toma de decisiones, las actuaciones más indecentes y erróneas, las tergiversaciones y las mentiras intencionadas de todas las presidencias estadounidenses desde Truman hasta Johnson, cinco presidencias en total, encaminadas todas ellas a perpetuar la presencia estadounidense en el Sudeste Asiático sin que ningún presidente, uno detrás de otro, se atreviera a abandonar esa región que estaba en plena efervescencia anticolonialista expulsando a los europeos, a pesar de que en varias ocasiones así se aconsejaba, por miedo a ser tachado de poco enérgico con el comunismo, una actitud heredada de presidente a presidente y perpetuada por sus equipos de consejeros y que provocó la primera escalada directa con Eisenhower desde 1959, a la que siguió la intervención militar directa de Estados Unidos con Kennedy para 1961-62, y finalmente la guerra con Johnson en 1964-65.

De forma esquemática, los Pentagon Papers revelaban que el primer presidente en fijarse en Indochina fue Truman, quien financió a los franceses para recuperar su excolonia a pesar de saber que los franceses luchaban contra un movimiento nacional apoyado por los vietnamitas que además contaba con la legitimidad que tenían todos los movimientos emancipadores de Asia y África de la post-guerra que pretendían acabar con los obsoletos imperios coloniales europeos. El siguiente presidente, Eisehhower, apoyó al brutal dictador de Vietnam del Sur para que no se celebraran las elecciones que unificarían Vietnam previstas para 1956 según los acuerdos de Ginebra de 1954; EE.UU se opuso ferozmente a la celebración de unas elecciones al mismo tiempo que declaraba promocionar la democracia en Vietnam. Kennedy amplió la participación estadounidense de 1.000 a 16.000 hombres mintiendo a la opinión pública y al Congreso, al asegurar que sólo harían falta algunos pocos miles de asesores militares para estabilizar Vietnam y combatir al comunismo, a pesar de que los propios asesores de Kennedy la dijeron que sin el envío masivo de unidades de combate, Vietnam era una causa perdida. Johnson continuó con las mentiras, comenzando con el Incidente del Golfo de Tonkín, hasta lograr que el Congreso le autorizara para lanzar una gran guerra en Vietnam. Todos los presidentes querían a toda costa evitar perder Indochina a manos de los comunistas bajo su mandato y usando la excusa de ayudar al pueblo libre de Vietnam del Sur. Y por último Nixon, que tras desescalar la guerra y reducir la presencia estadounidense desde 1969, la prolongó otros cuatro años más a base de gigantescas campañas de bombardeos sobre Vietnam del Norte, tras haber anunciado en las elecciones de 1968 que acabaría con la guerra.

Ellsberg, tras leer los Papers hasta en dos ocasiones, se dio cuenta de que había sido una guerra estadounidense desde el principio. Además del boicot a las elecciones de 1956, en 1961 Kennedy había enviado tropas, violando los Acuerdos de Ginebra. Johnson por su parte concentró las fuerzas antes de lo que había dicho. Las mentiras oficiales de las sucesivas administraciones podían comprobarse claramente en los Pentagon Papers. Ellsberg, que tenía por su condición de empleado de la Rand Corporation libre acceso a los 
Pentagon Papers, tras analizar el estudio completo tomó conciencia de los errores, las tergiversaciones y las mentiras de las sucesivas administraciones estadounidenses respecto a Vietnam, y decidió que debía difundir y hacer público de alguna manera el estudio. Pero se trataba de un estudio hecho a nivel interno, no pensado para ser divulgado al público. La parte más escabrosa revelaba que el gobierno de Johnson ya sabía desde al menos finales de 1966, el segundo año de la guerra directa de EE.UU en el Sudeste Asiático, que la guerra no podría ser ganada nunca en los términos concebidos por los planificadores de Washington (ir a Vietnam, acabar para siempre con la insurgencia comunista por medios militares convencionales, y retirarse), y que tenía escasísimas probabilidades de lograr la estabilización y la autodefensa de Vietnam del Sur, el objetivo mínimo perseguido, aún empleando hasta medio millón ó más de soldados estadounidenses. Se asumía por tanto que la prolongación de la guerra sólo sería un gigantesco gasto y provocaría muchas más bajas que las que fueron admitidas en ese momento públicamente. Aún asumiendo todo ello, el tándem Johnson - McNamara prolongó la guerra, y en buena parte lo hizo simplemente de cara a la opinión pública norteamericana, que si bien en 1968 apostaba mayoritariamente por una retirada, para 1966 no hacía más que recibir mensajes en tono de victoria, y no hubiera podido digerir una retirada repentina, que además hubiese supuesto el hundimiento y la muerte política de la Administración Johnson.

Los Pentagon Papers demostraban, además de las mentiras oficiales que condujeron a la Guerra de Vietnam, el enorme cinismo de los planificadores y funcionarios de alto nivel, sobre todo de la época de Johnson, cuando se inició la guerra, cinismo de cara a la opinión pública, y cinismo al no tener apenas en cuenta el enorme coste humano que significaba la contienda. Ellsberg revelaría décadas más tarde cómo en una ocasión durante 1967 acompañó en un vuelo de regreso a EE.UU desde Vietnam a Robert McNamara, y cómo éste le pidió en pleno vuelo que diera su opinión ante un grupo de asesores, sabiendo que la opinión de Ellsberg era ya entonces que la guerra era básicamente inviable (es decir, que McNamara opinaba lo mismo en privado), y cómo sin embargo nada más bajar del avión, el Secretario de Defensa hizo una breve declaración a la prensa diciendo que la guerra iba por buen camino y volvía de Vietnam convencido de los progresos y de que la guerra se estaba ganando. Ese era el grado de cinismo e hipocresía en el que se movía la Administración Johnson respecto a Vietnam ya en 1967.

En Octubre de 1969 Ellsberg comenzó a fotocopiar en secreto las 7.000 páginas de documentos del Informe considerados como "top secret" de la copia de la caja fuerte de la Rand Corporation. Le ayudó su compañero de la Rand Corporation y activista anti-Vietnam, Anthony Russo. Ambos estuvieron fotocopiando varias semanas, siempre con el mismo método: Ellsberg sacaba diariamente algunos capítulos del Informe de la caja fuerte en su maletín, y los fotocopiaban de madrugada en una fotocopiadora propiedad de Russo. Se trataba de actos que violaban todos los acuerdos de confidencialidad que los empleados de la Rand Corporation debían firmar, que implicaban condenas de cárcel, y que implicaban indirectamente a la propia Rand Corporation como colaboradora del Departamento de Defensa; tiempo después, se dañarían 
reputaciones de dirigentes de la Rand que habían avalado personalmente a Ellsberg, empezando por el propio director, que finalmente fue destituído.

Una vez fotocopiado todo el Informe, Ellsberg se decidió en 1970 a hacerlo público. Al principio buscó alguna fórmula legal: trató infructuosamente con destacados líderes contrarios a la guerra, como el Senador William Fullbright, entonces presidente del comité de relaciones exteriores del Senado y destacado líder anti-Vietnam, quien sin embargo se mostró comprensivo pero se negó a colaborar para no violar la ley, aún a pesar de que un senador no podía ser procesado al tener inmunidad incluso por difundir secretos oficiales. Lo intentó también con otro destacado opositor a la guerra, George McGovern, quien tampoco se mostró dispuesto porque una acción así dañaría su carrera política (en 1972 sería el candidato demócrata a la presidencia, perdiendo contra Nixon). Tras todos los intentos fallidos, finalmente Ellsberg se decidió a hacer público el Informe a través de un viejo amigo que conoció en Vietnam, el periodista Neil Sheehan, corresponsal del New York Times. Fue así como le filtró todo el Informe y el 13 de Junio de 1971 comenzó la publicación de los Pentagon Papers con la primera de nueve entregas.

\section{Acontecimientos Tras la Publicación de los Pentagon Papers}

Las reacciones tras la divulgación de los Pentagon Papers fueron enormes; en lo que respecta al poder ejecutivo, Nixon, obsesionado ya para entonces con las constantes filtraciones sobre su gobierno y las decisiones de su gabinete que se estaban produciendo, consideró inicialmente a los Pentagon Papers como documentos que no le incriminaban, ya que implicaban a administraciones anteriores a la suya, abarcando sólo hasta 1967, y casi todas ellas de su partido rival, el demócrata. Sin embargo posteriormente Nixon y su Secretario de Estado, Henry Kissinger, consideraron que la filtración de documentos secretos era muy grave y podía tener repercusiones. La Casa Blanca trató entonces de detener la publicación por todos los medios, e inició una persecución personal contra Ellsberg y contra todo lo que éste representaba, así como contra el New York Times para que detuviera la publicación. Para Nixon y Kissinger, Ellsberg era un traidor, y debía tratársele como tal.

La Administración Nixon logró por orden de su Fiscal General, John Mitchell, un mandamiento judicial para prohibir la publicación, e incluso agentes del FBI se personaron en las dependencias del periódico ordenando parar las imprentas. Pero la prensa norteamericana hizo causa común con el New York Times y por la libertad de prensa y la libertad de expresión, y un buen número de periódicos de todo el país tomaron el testigo del diario neoyorquino y continuaron publicando la práctica totalidad de los Pentagon Papers. El mensaje era claro: si el gobierno quería evitar la publicación, debería demandar a todos los periódicos uno a uno, en lo que hubiese sido un proceso largo y tormentoso, y un atentado muy grave contra la libertad de prensa, aún tratándose de la divulgación de documentos de alto secreto. Finalmente, el 30 de Junio de 1971 y en un fallo histórico, el Tribunal Supremo declaró legal la publicación. 
En el inicio de todos éstos acontecimientos se desconocía quien había filtrado la información; el New York Times, fiel a la máxima del periodismo de investigación nunca reveló su fuente, y Ellsberg se refugió en la clandestinidad hasta que trascendió a la opinión pública su figura, mientras que continuó suministrando información a la prensa, ya en el punto de mira del $\mathrm{FBI}$, que ya le consideraba el principal sospechoso. Incluso Walter Cronkale le hizo una entrevista clandestina en un lugar secreto, donde Ellsberg expuso sus motivaciones. Finalmente, y aconsejado por su abogado, se entregó en Boston el 28 de Junio. Al día siguiente, el 29 de Junio, un senador antibelicista, Mike Grava, leyó públicamente más de la mitad del Informe durante horas, haciéndolo así oficialmente público y facilitando el fallo del Tribunal Supremo del día siguiente.

Semanas después, para el verano de 1971, y ante la imposibilidad de detener la publicación de los Pentagon Papers y para evitar posteriores filtraciones como aquella, la Administración Nixon puso en marcha desde el mismo Despacho Oval una unidad que se conocería como "los fontaneros" (para "tapar filtraciones") con la intención de manchar clandestinamente la imagen de Ellsberg ante la opinión pública, dando a entender la peligrosidad que Nixon y Kissinger atribuían a Ellsberg. Esa unidad irregular, que se prodigó durante casi un año en acciones totalmente al margen de la ley y violando toda clase de normas para lograr, supuestamente, objetivos políticos de cara a las elecciones de 1972, daría lugar un año más tarde al estallido del Escándalo Watergate, por lo que las revelaciones de Ellsberg pusieron en marcha el suceso que acarrearía el mecanismo de caída de la Administración Nixon, que dimitió de la presidencia en Agosto de 1974. En una cinta hecha pública años después del Watergate, que registraba conversaciones en el Despacho Oval del 14 de Junio de 1971, el día después de la primera publicación del New York Times, el asesor de Nixon, Bob Haldeman, le exponía al presidente la situación en éstos términos: "al individuo ordinario, todo ésto le parecerá un manojo de gobbledygook; pero de ésto viene algo muy claro: usted no puede confiar en el gobierno, no puede creer lo que dicen, ni confiar en su juicio. Y la inhabilidad implícita de los presidentes, algo aceptado tradicionalmente en EE.UU, se está viendo afectada gravemente por todo esto, porque demuestra que la gente hace cosas que el presidente desea hacer aún cuando sea incorrecto, y el presidente puede ser incorrecto". Éstas palabras de un colaborador tan cercano a Nixon demuestra la turbia atmósfera que presidió la Administración Nixon.

Ellsberg y Russo fueron acusados de robo, conspiración, espionaje y violación de la Espionage Act. Éstos cargos incluían acusaciones de recepción, retención y comunicación de documentos de la defensa nacional. El FBI, a instancias de la Casa Blanca y del Fiscal General, lanzó una auténtica cacería humana contra él para destruír su reputación. Un año más tarde, y ya en el contexto del Escándalo Watergate, se supo que durante esa cacería sobre Ellsberg, justo tras su entrega a la justicia, el grupo denominado "los fontaneros" efectuó su primera acción ilegal irrumpiendo en Septiembre de 1971 en la consulta del psiquiatra de Ellsberg, Louis Fielding, en Los Angeles, para lograr expedientes psiquiátricos que pudieran hacerse públicos desacreditando así la imagen de Ellsberg. Tras un largo proceso judicial en el que Ellsberg y su colaborador Athony Russo llegaron a enfrentarse hasta a 115 
años de cárcel, el juicio contra él fue anulado y sobreseído en 1973 al constatarse que la Administración Nixon y la Fiscalía habían cometido toda clase transgresiones de la ley y de atropellos legales contra ambos, incluyendo prevaricación, supresión de pruebas, ocultación de testigos, obstrucción a la justicia, e incluso robo de información. La Administración Nixon, para lograr una dura condena contra Ellsberg y Russo, mintió, estafó, ocultó pruebas, cometió allanamiento e incluso trató de comprar al juez del caso, por lo que finalmente el juicio fue declarado nulo.

La anulación del juicio contra Ellsberg fue una consecuencia más, aunque fuese residual, del Escándalo Watergate, surgido a mediados de 1972, justo un año después de las revelaciones de Ellsberg sobre los Pentagon Papers. La constitución de la unidad de "los fontaneros" tuvo su origen en las filtraciones de Ellsberg, aunque posteriormente se usó a éste grupo para todo tipo de finalidades, todas ellas ilegales. Tras dos largos años de escándalo y el inicio de un proceso constitucional de Impeachment contra Nixon, el presidente dimitió en Agosto de 1974. Su sustituto en la presidencia, Gerald Ford, suprimió la política de Nixon denominada "vietnamización", consistente en "devolver" la guerra a los vietnamitas prestando sólo asistencia técnica (sin presencia militar estadounidense) al gobierno de Vietnam del Sur, desentendiendo completamente a Estados Unidos del Sudeste Asiático; como consecuencia, Vietnam del Norte, notando la total falta de presión norteamericana, planeó una gran ofensiva en el Sur para finales de 1974, resultado de la cual unos meses después el gobierno de Vietnam del Sur colapsó ante la pasividad de EE.UU, y la Guerra de Vietnam concluyó definitivamente el 30 de Abril de 1975 con la toma de Saigón y la victoria comunista en todo Vietnam.

Ellsberg actuó en todo momento no con afán de notoriedad, sino convencido de que la opinión pública estadounidense, e incluso el Congreso, que en 1964 había aprobado la Resolución del Golfo de Tonkín que dio luz verde a la guerra, aprobación hecha bajo engaños como los Pentagon Papers demostraban, y el Senado habían sido engañados desde el poder ejecutivo, y de que todo el mundo debía saber las verdaderas motivaciones de la guerra para detener definitivamente ese conflicto que ya por entonces, 1971, le había costado la vida a 55.000 estadounidenses. Cuando se publicaron los Pentagon Papers, el mundo se enteró del doble discurso de las sucesivas administraciones estadounidenses, ya que el discurso oficial durante décadas decía una cosa, mientras que las intenciones y las acciones obraban de forma diferente. Así, en 1955 la Administración Eisenhower boicoteó deliberadamente las elecciones democráticas previstas para todo Vietnam para 1956, consciente de que éstas serían ganadas por los comunistas de forma democrática, cuando el discurso oficial estadounidense era combatir al comunismo e imponer la democracia en el Sudeste Asiático. Los Pentagon Papers demostraban que la Guerra de Vietnam fue una causa perdida prácticamente desde los inicios de la intervención directa estadounidense (1964-65), que era una guerra que estaba estancada en sus objetivos y en su desarrollo, que tenía otras finalidades diferentes a las expuestas en el discurso oficial, y que todos éstos aspectos eran sobradamente conocidos por los dirigentes estadounidenses, pero uno tras otro fueron dejando a un lado éstas objeciones y prolongaron la guerra indefinidamente, hasta llegar a la Administración Nixon, que si bien limitó la 
guerra iniciando la retirada estadounidense, la prolongó durante cuatro años más e incluso la extendió a Camboya, provocando la mitad de las bajas totales estadounidenses, y obligando a aceptar a Vietnam del Norte acuerdos que éste ya estaba dispuesto a aceptar en 1968.

El saldo final de la Guerra de Vietnam en sus años de intervención estadounidense (1964-73) fue de 2 millones de vietnamitas muertos y 58.000 norteamericanos fallecidos, cuyos nombres fueron gravados en un Muromemorial en Washington edificado en 1982. Sin embargo, no se produjo un "efecto dominó" en el Sudeste Asiático tal como habían pronosticado los geoestrategas estadounidenses desde 1955, no extendiéndose el comunismo desde Vietnam a otras regiones de Asia, ni tan siquiera a sus países vecinos, otra prueba más de la falacia y las mentiras de los planificadores de la guerra.

\section{El Legado de Ellsberg}

Las revelaciones y la actitud de Ellsberg se han convertido en todo un ejemplo de coraje, compromiso y honestidad personal, ya que renunció a su brillante carrera como funcionario de planificación de alto nivel en el gobierno por hacer valer sus valores personales y tras comprobar que la guerra que él mismo había ayudado a planificar era un gran error. Asumiendo que revelar secretos oficiales es un delito, si se admite que los presupuestos de la Guerra de Vietnam eran básica y manifiestamente falsos y tergiversados desde el principio, ya que incluso la implicación estadounidense en las primeras operaciones bélicas en 1964 se basaron en mentiras oficiales (es un hecho que se mintió al Congreso respecto al Incidente del Golfo de Tonkín para que éste sancionase la guerra), los actos de Ellsberg son, como mínimo, moralmente aceptables, y a partir de ahí la historia en éstos últimos cuarenta años ha ido dictando sentencia al valorar hoy, en perspectiva histórica, positivamente el legado de Daniel Ellsberg. Otra cosa muy distinta es considerar que cualquiera que se oponga a una guerra y revele secretos oficiales está siguiendo los pasos de Ellsberg y está haciendo lo correcto. El caso de Assange es similar en la actualidad, y si bien se trata de otra guerra, la Guerra Global contra el Terrorismo iniciada en Octubre de 2001 y concentrada hoy en dos escenarios, Irak y Afganistán, con tintes negativos en lo tocante al recorte de libertades y cada vez menos transparente, se debe analizar más exhaustivamente su actuación, y aún está por ver la perspectiva histórica de los actos del creador de Wikileaks.

Ellsberg, tras sus actuaciones se convirtió desde mediados de los 1970's en un activista político que denuncia las mentiras que usa el poder y sus abusos, además de tratar de frenar la acumulación de poder de los gobiernos. Una vez exonerado de sus acusaciones sobre los Pentagon Papers, participó en protestas diversas: ha denunciado intervenciones militares de EE.UU en otros países, así como la proliferación nuclear, llegando a ser detenido hasta en 60 ocasiones. Una de sus últimas detenciones tuvo lugar en San francisco en 2008 durante una manifestación contra la Guerra de Irak. Actualmente trabaja para "Truth Telling Project", una organización dedicada a promover la libertad de conciencia entre los funcionarios públicos para denunciar todo tipo de actos 
ilegales o poco éticos desde los poderes públicos. Da conferencias en universidades y centros de estudio por todo el mundo. $Y$ es que Ellsberg considera, en base a su propia experiencia, que exponer las mentiras de un gobierno es algo que implica un enorme riesgo personal para cualquiera, máxime para un funcionario público, incluso en una democracia. Es por ello que en muchos aspectos cree que la figura del disidente, propia de los regímenes totalitarios, también existe en cierto modo aunque más atenuada en las modernas democracias, y él es un buen ejemplo. También opina que el secreto, al igual que el poder, tiene un enorme poder caústico y corrosivo, corrompiendo a las personas.

Durante los meses de Febrero y Marzo de 2003, las semanas previas al ataque estadounidense sobre Irak, advirtió de la existencia de un posible "panorama del Golfo de Tonkín" que la Administración Bush podría usar para justificar la guerra, llegando a desafiar a la Administración a que demostrara que no ocurría así y denunciando la propaganda oficial en pro de una invasión de Irak. Llegó a contactar y a elogiar a Scott Ritter, un exagente secreto de la CIA que tras prestar servicios en Irak durante los años 1990's, terminó denunciando las maniobras del gobierno de EE.UU y de la CIA contra los esfuerzos de la ONU para evitar una intervención militar en Irak, así como el uso de información obtenida por los inspectores de la ONU en Irak para uso militar por parte de EE.UU, maniobras que desembocaron en la campaña de bombardeos que la Administración Clinton lanzó sobre Irak, aún gobernada por Sadam Hussein, en Diciembre de 1998, campaña que continuó en 1999. Ritter se convirtió desde finales de los 1990's en un "nuevo Ellsberg", un exfuncionario de alto nivel que denunció públicamente las mentiras de su gobierno y que desde entonces es prácticamente un "disidente" de la política exterior de EE.UU. Otro nombre que también se ha unido a éste "club" es el de Robert Baer, un exagente de la CIA que estuvo destinado en el Líbano y otros lugares de Oriente Medio durante los 1980's y los 1990's y que abandonó desencantado la agencia en 1995, desvelando muchas de las actividades, algunas ilegales, de la CIA, así como errores de cálculo de EE.UU en ésta región.

Ellsberg llegó a animar en 2003 a todos los funcionarios del gobierno que tuvieran conocimiento de las mentiras oficiales sobre la Guerra de Irak para que las hicieran públicas. En Noviembre de 2005 fue arrestado por violar una ordenanza estatal mientras protestaba contra el Presidente Bush por la Guerra de Irak. En Septiembre de 2006, y en pleno tratamiento internacional contra Irán por parte de EE.UU y varios países europeos por el programa nuclear iraní, Ellsberg escribió en la revista "Harper" que deseaba y esperaba que alguien de la Administración filtrara informes secretos sobre un hipotético y entonces muy probable plan proyectado supuestamente para 2007 para invadir Irán, antes de que se produjera esa invasión, de la que se llegó a especular que contaría con 300.000 soldados estadounidenses. También Ellsberg se mostró partidario de equiparar la Carta de las Naciones Unidas a las leyes estadounidenses, y de instituír y dar plenos poderes a la Corte Penal Internacional, un proyecto nacido en 1998 a partir del Caso Pinochet.

Uno de los grandes legados de Ellsberg, a parte de su coraje personal, de la lucha por la libertad de conciencia y por la libertad de prensa, es el compromiso 
personal y la postura de que no siempre se puede e incluso se debe ser "políticamente correcto", ya que en ocasiones, y según la mentalidad de cada persona, lo correcto es tomar partido en base a principios éticos, si bien ello puede conllevar graves consecuencias personales por entrar en conflicto con leyes de los Estados. Las revelaciones de Ellsberg supusieron un antes y un después en la forma de tratar y de tutelar las actividades de los gobiernos en las democracias, especialmente cuando se trata de actividades secretas y de espionaje, y sobre todo cuando esas actividades han podido desembocar en guerras cimentadas en mentiras y tergiversaciones donde se producen muertos a diario, como sucedía en Vietnam, o actualmente (si bien el contexto es distinto) en Irak y Afganistán.

Desde todas las ópticas, es un hecho que las filtraciones de Ellsberg de 1971 pusieron en marcha una maquinaria (la opinión pública, su juicio, la creación de "los fontaneros", el Watergate, las comisiones de investigación, el "cuarto poder") que si en un principio fue traumática, finalmente fortaleció a la democracia norteamericana.

\section{Vietnam (1971) y Afganistán-Irak (2010): la Historia se Repite}

En 1971 Daniel Ellsberg filtró un informe de 7.000 páginas sobre la Guerra de Vietnam, y a lo largo de 2010 Wikileaks filtró varias entregas de cientos de miles de documentos sobre las Guerras de Irak y Afganistán. En 1971 la intervención estadounidense en Vietnam ya languidecía, y aunque en 2010 la presencia militar estadounidense en Afganistán e Irak era aún nutrida y no había grandes muestras de hostilidad entre la población norteamericana contra tales guerras, todo apunta a que también flaquea la posición de EE.UU en ambos países, y su presencia tendrá que replantearse en el sentido de una lógica e inevitable disminución, hasta llegar a una retirada final. Algunos países, como Holanda, ya anunciaron a finales de 2010 que en unos meses retirarían a sus tropas de Afganistán.

La filtración de los "Pentagon Papers" y su publicación por el New York Times y otros periódicos provocó uno de los mayores escándalos políticos en EE.UU, abriendo además una enorme controversia en lo tocante a la libertad de prensa y a la libertad de expresión, siempre con el telón de fondo de la seguridad nacional. Las motivaciones de Ellsberg, tras ser uno de los arquitectos de la guerra entre 1964 y 1968, se basaban en su consideración de que la Guerra de Vietnam era tan injusta como mal planificada tras su prolongación, además de que tras participar en ella fusil en mano, tras ayudar a cimentarla, tras analizarla y tras leer hasta en dos ocasiones los Pentagon Papers, estaba convencido de que era imposible de ganar en los planteamientos y en la definición de la guerra clásica y que los estadounidenses se propusieron: destruír a la insurgencia comunista, hacerla desaparecer para siempre afianzando al gobierno pro-occidental de Saigón, y retirarse una vez estabilizada la situación. Ellsberg confiaba en que el apoyo popular a la guerra, ya inexistente para 1971, desaparecería por completo y se tornaría en total oposición tras conocerse la trayectoria irregular e incluso inconstitucional de varias administraciones estadounidenses (desde Truman hasta Nixon). 
Efectivamente, la publicación del informe no sólo dejó en entredicho la línea oficial de la guerra marcada desde 1964, aún vigente aunque con matices en 1971, sino que por una serie de acontecimientos terminaría provocando la dimisión del presidente Nixon en 1974. Sin embargo, en un principio, aún siendo una gran conmoción su publicación, no dañaron casi en absoluto al republicano Nixon, ya que en realidad dañaban la imagen de los presidentes anteriores a él, y casi todos demócratas, y no sólo no evitaron la enorme victoria electoral de Nixon en 1972, una de las mayores de la historia, si no que apenas lograron variar un ápice la agenda de la guerra que en su último año de participación estadounidense, 1972, sufrió una escalada con dos gigantescas campañas de bombardeos sobre Vietnam del Norte en Mayo y Diciembre, las Operaciones Linebacker I y II, por lo que la guerra no terminaría para EE.UU hasta Enero de 1973 con los Acuerdos de París que aún adjudicaban a Washington una tutela sobre la guerra, si bien se retirában completamente las fuerzas estadounidenses del Sudeste Asiático. Incluso en ese paréntesis de casi dos años desde la filtración de 1971 hasta la retirada definitiva de 1973, Nixon enviaría más soldados aún, en pleno descenso del número de efectivos estadounidenses, e incrementaría de forma brutal sus bombardeos sobre Vietnam, calificados entonces como "para hacer retroceder a Vietnam del Norte a la edad de piedra". Y todo ello con unas revelaciones, las de los Pentagon Papers, mucho más valiosas y sorprendentes que las que ha filtrado Wikileaks sobre Irak y Afganistán en 2010, ya que los Papers eran toda una radiografía de la Guerra de Vietnam desde el principio. Los Pentagon Papers demostraban cómo las administraciones de Truman, Eisenhower, Kennedy y Johnson habían negado una solución al problema que comenzó a representar Vietnam desde 1945, negando ayuda a Ho Chi Min (que fue aliado de EE.UU durante la ocupación japonesa de Vietnam entre 1940-45), también negándosela a los franceses, si bien Truman les financió para combatir a los insurgentes vietnamitas, hasta que los franceses fueron expulsados de Vietnam en 1954, y boicoteando las elecciones previstas para 1956. Johnson dio el salto cualitativo al implementar la intervención masiva norteamericana desde 1964 con el controvertido Incidente del Golfo de Tonkín, y manipuló y mintió a la opinión pública y al Congreso, además de saltarse varios cauces constitucionales para ir a la guerra.

Si todo el asunto Ellsberg hubiera sucedido hoy, sólo tendría que haber escaneado los documentos y colgarlos en Internet. Eso es precisamente lo que hace Wikileaks en la actualidad: recibe documentos y los filtra en la web de forma anónima para revelarlos a la opinión pública de todo el mundo, aunque curiosamente también acude a periódicos de primera talla internacional para difundir los contenidos dándoles así más apariencia de veracidad y más publicidad. La analogía histórica entre las filtraciones de 1971 y 2010 son, pues, enormes. 